\title{
Investigation and Analysis on the Satisfaction of Doctoral Training Quality in Chongqing
}

\author{
Hu Weili ${ }^{1}$, Chen Dilong ${ }^{2, *}$ \\ ${ }^{1}$ Graduate School, Chongqing Medical University, Chongqing, China \\ ${ }^{2}$ President Office, Chongqing Three Gorges Medical College, Chongqing, China \\ Email address: \\ 184673716@qq.com (Hu Weili), 775832160@qq.com (Chen Dilong) \\ ${ }^{*}$ Corresponding author
}

To cite this article:

Hu Weili, Chen Dilong. Investigation and Analysis on the Satisfaction of Doctoral Training Quality in Chongqing. Higher Education Research. Vol. 5, No. 1, 2020, pp. 9-16. doi: 10.11648/j.her.20200501.13

Received: June 5, 2019; Accepted: January 2, 2020; Published: January 16, 2020

\begin{abstract}
Through large-scale data collection and analysis, in-depth investigation and research, combined with the vertical and horizontal comparison of Postgraduates inside and outside the city, this study will finally show the overall advantages and gaps of graduate education in the form of data. Guided by the macro strategic development of Chongqing's economic and social construction, aiming at the current gap, the corresponding policy education is promoted from the three levels of the state, Chongqing and each training unit, so as to provide intellectual support for comprehensively improving the quality of graduate education in Chongqing. Through consulting relevant documents, define the key concepts such as graduate quality, graduate education quality, graduate training quality and graduate education evaluation; analyze the overall goal of graduate education; understand the current situation of graduate education quality evaluation in relevant provinces and cities; comprehensively collect the current situation of graduate education quality in our city, summarize and sort out the quality quantitative indicators; and influence the quality of graduate education The evaluation factors of quantity are summarized. This paper investigates the basic situation of doctoral education in Chongqing, investigates and analyses the satisfaction degree of doctoral training quality of six doctoral training institutions in Chongqing by means of questionnaires, and analyses the relevant indicators of higher and lower satisfaction degree of doctoral training quality in Chongqing, and thinks about further improving the satisfaction degree of doctoral training quality in Chongqing.
\end{abstract}

Keywords: Doctoral Students, Training Quality, Satisfaction, Investigation and Analysis

\section{Introduction}

At the end of 2014, China's GDP is more than twice that of Japan, which is threatening the position of the United States as the world's largest economy. The rapid and sustainable development of the economy and society shows that China's overall national strength and global influence have improved significantly. With the increasing international influence, competition and challenges remain the main problems facing our country at present. The core of competition lies in talents. At present, the scale of doctoral education in China has surpassed that in the United States and ranked first in the world. However, there is still a big gap between the quality of doctoral training and that of developed countries, especially in terms of original innovation ability [1]. Therefore, the quality of doctoral training in our country has not been recognized internationally, and even some individual excessive scholars suggested abolishing doctoral education in our country.

Under the above background, the Chongqing Municipal People's Government has given great concern to the development of doctoral education and the further improvement of the quality of doctoral training in Chongqing. The Office of Chongqing Academic Degree Committee and Chongqing Education Committee decided to conduct a large-scale investigation and study to accurately grasp the basic situation of doctoral education in Chongqing, comprehensively understand the current situation of doctoral training quality in Chongqing, and provide decision-making reference for the development and reform of doctoral education. 


\section{Research Contents and Main Methods}

In March 2013, the office of Chongqing Academic Degree Committee, the Academic Degree Management and Graduate Education Department of Chongqing Education Committee carried out a survey on the quality of doctoral training in six doctoral training units in Chongqing [2]. As an important subject of the reform of postgraduate education and teaching in Chongqing, the Graduate School of Chongqing Medical University was entrusted with the task of conducting the survey. The research work mainly centers on five main aspects: scale, structure, quality, benefit and culture. It comprehensively considers four main quality concepts: scientific research achievements, practical training, career orientation and benefit orientation, and comprehensively designs a questionnaire on the quality of doctoral training in Chongqing.

The first round of special research was conducted from May 1 to May 31, 2013. The main research methods were questionnaire survey, expert interview, group interview and seminar. The research team conducted a questionnaire survey on six doctoral training institutions [3], including
Chongqing University, Southwest University, Third Military Medical University, Chongqing Medical University, Southwest University of Political Science and Law, Chongqing Jiaotong University and so on. The subjects were mainly doctoral students, doctoral supervisors, doctoral education administrators and graduate doctoral students. According to the training scale of doctoral students in six universities, the number of questionnaires was determined. A total of 1480 questionnaires were sent out. A total of 1317 valid questionnaires were collected, and the effective rate was $88.9 \%$ (Table 1 ).

Based on the investigation and research work of doctoral training quality in Chongqing, this paper intercepts part of the survey data and analysis reports, and focuses on the analysis of the satisfaction degree of doctoral training quality among different related subjects of doctoral education in Chongqing, such as in-school doctoral students, doctoral supervisors, managers and some graduate doctoral students, and on the basis of the above subjects' evaluation of doctoral training quality in Chongqing. This paper also considers how to further improve the quality of doctoral training in our city.

Table 1. Questionnaire of Doctoral Training Quality in Chongqing.

\begin{tabular}{|c|c|c|c|c|c|}
\hline University Name & $\begin{array}{l}\text { Questionnaire for } \\
\text { Doctor Students in } \\
\text { School }\end{array}$ & $\begin{array}{l}\text { Questionnaire of } \\
\text { Doctor 's Supervisor }\end{array}$ & $\begin{array}{l}\text { Questionnaire for } \\
\text { Doctor 's Graduate } \\
\text { Administrators }\end{array}$ & $\begin{array}{l}\text { Questionnaire for } \\
\text { Graduated Doctor } \\
\text { Students }\end{array}$ & Total \\
\hline Chongqing University & 400 & 50 & 20 & 50 & 520 \\
\hline Southwest University & 200 & 50 & 20 & 50 & 320 \\
\hline Third Military Medical University & 150 & 30 & 10 & 30 & 220 \\
\hline Chongqing Medical University & 100 & 30 & 10 & 30 & 170 \\
\hline Southwest University of Political Science and Law & 100 & 30 & 10 & 30 & 170 \\
\hline Total & 1000 & 200 & 80 & 200 & 1480 \\
\hline
\end{tabular}

\section{Survey on the Basic Status of Doctoral Education in Chongqing}

\subsection{Doctoral Education Scale}

In 2013, Chongqing has a total of doctoral training institutes, with 1,233 full-time doctoral students enrolled, including 1211 academic degrees, 22 professional degrees, 4275 doctoral students, 1278 on-the-job doctoral tutors and doctoral degrees awarded. In terms of scale, our city ranks second only to Sichuan in the five western provinces (Sichuan, Chongqing, Yunnan, Guizhou and Tibet), and fourth among the four municipalities directly under the Central Government (Beijing, Shanghai, Tianjin and Chongqing), which is closer to Tianjin.

\subsection{Doctoral Education Structure}

First, the structure of subject categories. At present, graduate education in Chongqing has covered all 13 subject categories. From the point of view of the students, the proportion of doctoral education in traditional Chinese medicine is the highest, reaching $33.64 \%$, followed by engineering and law. Economics, history and art accounted for the lowest proportion, $1.68 \%, 0.76 \%$ and $0.31 \%$ respectively. The disciplines were complete, but the proportion of students in different disciplines did not fully meet the needs of economic, social and cultural development in Chongqing. The second is the structure of degree types [4]. The proportion of professional degree in the enrollment scale of doctoral students is $1.78 \%$, which is lower than $2.62 \%$ in the whole country. It is necessary to strengthen the education of doctoral students with professional degree. Thirdly, the gender structure, in which $38.85 \%$ of the doctoral students are female and 1660 are female, and male students still play a dominant role in doctoral education. Fourthly, the age structure of doctoral students in the university is the age group of 26-28 years old, accounting for $37.5 \%$. Among the graduates who study full-time doctoral degree, the students who work for a short time after graduation are still the main ones.

\subsection{Doctoral Year System}

At present, some training units in Chongqing have begun to implement flexible education system. The basic education system for doctoral students is three to six years, and most universities are four years. Questionnaire shows that the three-year system of doctoral students has been approved by most of the doctoral students $(59.33 \%)$, while most of the 
tutors $(50.76 \%)$ think that the four-year system of doctoral students is more reasonable. Doctoral students prefer to graduate in a short time and get their degree, but tutors tend to have a longer education system from the perspective of guaranteeing the quality of postgraduate training [5]. Therefore, on the basis of maintaining the existing educational system, smoothly promoting the reform of flexible educational system is in line with the actual situation of postgraduate education in Chongqing.

\subsection{Time Allocation in Training Link}

Course learning, scientific research and practical ability training constitute the main link of doctoral training. The proportion of each link in the process of graduate training can reflect the emphasis of doctoral training of different degree types. The survey shows that the average proportion of scientific research in academic degree doctoral students is $40 \%-50 \%$ of the total learning time, and the average proportion of practical skills training in professional degree doctoral students is $20 \%-30 \%$ of the total learning time (Table 2).

Table 2. Time allocation in doctoral training\%.

\begin{tabular}{lll}
\hline Training link & Academic Degree & Professional Degree \\
\hline Course learning & $10-20$ & $20-30$ \\
Scientific research & $40-50$ & $10-20$ \\
Practical Ability Training & $10-20$ & $20-30$ \\
Rest and recreation & $>10$ & $10-20$ \\
\hline
\end{tabular}

The above data show that most of the training units in our city have basically established different doctoral training modes for different degree types. By focusing on the training links, we can ensure the realization of the training objectives for doctoral students of different degree types. At the same time, the lack of practice time for professional degree doctoral students is inconsistent with the overall training objectives of professional degree graduate education in China.

\subsection{Basic Situation of Doctoral Tutors}

From the overall situation of Chongqing, the current implementation of the tutorial system is more traditional, the single tutorial system is more common, some universities have begun to implement the "double tutorial system" to train doctoral students with professional degrees, and a few universities have begun to study the introduction of tutorial group system into the training of doctoral students with professional degrees [6].

In terms of the number of graduate students supervised by tutors, the number of graduate students supervised by tutors in Colleges and universities in our city is generally large, with an average of 3.19 doctoral students supervised by each doctoral tutor. Doctoral supervisors also take on the task of guiding postgraduates, so the average proportion of one doctoral supervisor guiding postgraduates is higher, resulting in less communication time between tutors and students. In the surveyed doctoral students, the average number of communication between teachers and students is 3.33 times per month.

Guiding doctoral students to write dissertations is one of the main tasks of tutors. Doctoral students are satisfied with the work of tutors. Most doctoral students think that tutors help them to write dissertations (Table 3). However, in addition to guiding doctoral students to write dissertations, the influence of tutors on doctoral students'academic career is not enough. The survey results show that tutors have a greater impact on doctoral students'academic attitudes, academic integrity and moral accomplishment, while their academic interests and practical abilities are relatively small (Table 4).

Table 3. Assistance of tutors to doctoral students in writing dissertations in Chongqing\%.

\begin{tabular}{|c|c|c|c|c|c|}
\hline Different degree types & Greatly & More & Commonly & Less & Very small \\
\hline Academic Degree & 26.27 & 39.93 & 26.09 & 4.38 & 3.33 \\
\hline Professional Degree & 19.70 & 37.88 & 30.3 & 6.06 & 6.06 \\
\hline
\end{tabular}

Table 4. The influence of tutors on doctoral students'academic career\%.

\begin{tabular}{|c|c|c|c|c|c|}
\hline Evaluation projects & Greatly & More & Commonly & Less & Very small \\
\hline Professional knowledge & 43.58 & 36.35 & 16.37 & 2.32 & 1.39 \\
\hline Academic interest & 36.56 & 36.8 & 22.42 & 2.83 & 1.39 \\
\hline Scientific Research Ability & 40.52 & 37.5 & 17.49 & 2.77 & 1.72 \\
\hline Academic Attitude & 54.53 & 34.5 & 9.57 & 0.80 & 0.61 \\
\hline Moral cultivation & 50.06 & 34.88 & 12.64 & 1.62 & 0.8 \\
\hline Practical ability & 39.82 & 37.1 & 19.38 & 2.79 & 0.92 \\
\hline Academic Credit & 53.29 & 34.93 & 10.01 & 1.25 & 0.52 \\
\hline
\end{tabular}

\section{Investigation and Analysis on the Satisfaction of Doctoral Training Quality in Chongqing}

Doctoral training quality evaluation system includes professional knowledge level, scientific research level, innovation ability, foreign language level, academic ethics level and so on. Different subjects have different understanding of the evaluation system and different emphasis on the evaluation system. Based on the training objectives, training process and basic qualities of high-level talents of doctoral students, and combined with the main evaluation indicators used in the national doctoral quality survey conducted by the Academic Degree Committee of the State 
Council, the Ministry of Education and the Ministry of Personnel in 2007, the research group refined the basic and professional knowledge level, the knowledge level of related disciplines [7], the level of foreign languages, the ability of innovation, the ability of organization and coordination, the sense of mission and the quality of doctoral students. 12 indicators, such as sense of responsibility, academic ethics, scientific research ability, dissertation quality, practical ability and academic integrity level, are used to examine the satisfaction of different subjects to the current quality of doctoral training in Chongqing [8].

\subsection{Emphasis of Different Subjects on Evaluation Index of Doctoral Training Quality}

Doctoral students, doctoral supervisors and managers generally believe that the top three evaluation indicators which can best reflect the quality of doctoral training are innovation ability, scientific research ability, basic and professional knowledge level. The understanding of the three indicators is basically the same, indicating that different subjects have a unified understanding of the core elements of the quality of doctoral training (Table 5).

Table 5. The Emphasis of Different Subjects on the Quality of Doctoral Education\%.

\begin{tabular}{llll}
\hline Evaluation projects & $\begin{array}{l}\text { Questionnaire for Doctor } \\
\text { Students in School }\end{array}$ & $\begin{array}{l}\text { Questionnaire of Doctor's } \\
\text { Supervisor }\end{array}$ & $\begin{array}{l}\text { Questionnaire for Doctor's } \\
\text { Graduate Administrators }\end{array}$ \\
\hline Basic and Professional Knowledge Level & 48.19 & 42.64 & 37.41 \\
Knowledge level of related disciplines & 38.3 & 18.6 & 22.3 \\
Foreign language proficiency & 15.23 & 20.93 & 6.47 \\
Innovation ability & 61.22 & 68.22 & 13.18 \\
Organizational and coordination capabilities & 17.58 & 16.28 & 12.4 \\
Sense of mission and responsibility & 6.91 & 56.59 & 11.51 \\
Academic moral level & 11.62 & 41.86 & 9.35 \\
Scientific Research Ability & 59.5 & 13.18 & 11.51 \\
Dissertation quality & 20.25 & 18.6 & 66.91 \\
practical ability & 21.35 & 33.81 & 18.71 \\
Academic Credit Level & 13.81 & 18.71 \\
\hline
\end{tabular}

\subsection{Survey on Doctoral Students' Satisfaction with Training Quality}

Overall, $\mathrm{Ph}$. D. students in our city think that they are good at academic integrity, ideological and moral level and dissertation quality, but poor in innovation ability, practical ability and knowledge level of related disciplines (Table 6).

Table 6. Doctor students' self-evaluation of training quality $\%$.

\begin{tabular}{llll}
\hline Evaluation projects & High & Commonly & Low \\
\hline Basic and Professional Knowledge & 53.08 & 44.62 & 2.31 \\
Level & 42.31 & 52.31 & 5.38 \\
Knowledge level of related disciplines & 46.15 & 49.23 & 4.62 \\
Foreign language proficiency & 37.69 & 54.62 & 7.69 \\
Innovation ability & 37.69 & 57.69 & 4.62 \\
Organizational and coordination & 34.62 & 60.00 & 5.38 \\
capabilities & 57.69 & 42.31 & 0 \\
Sense of mission and responsibility & 52.31 & 44.62 & 3.08 \\
Academic moral level & 54.62 & 43.08 & 2.31 \\
Scientific Research Ability & 54.62 & 43.85 & 1.54 \\
Dissertation quality & 46.92 & 47.69 & 5.38 \\
practical ability & 70.00 & 30.00 & 0 \\
Academic Credit Level & & & \\
Basic and Professional Knowledge & & \\
Level & &
\end{tabular}

\subsection{Indicators of Doctoral Students' Satisfaction with Self-cultivation Quality in Chongqing}

\subsubsection{Academic Credit Level}

The survey results show that academic integrity level is the most satisfactory aspect for doctoral students during their study period. Seventy percent of doctoral students say that they perform better in academic integrity. Thirty percent of doctoral students say that they do not perform well in academic integrity. No doctoral students think that they do not perform well in academic integrity.

\subsubsection{Ideological and Moral Level}

The results show that $\mathrm{Ph}$. D. students are satisfied with their ideological and moral performance in school. 57.69\% of Ph. D. students think that their ideological and moral level is higher. $42.31 \%$ of $\mathrm{Ph}$. D. students think that their ideological and moral level is general. No Ph. D. students think that their ideological and moral level is poor.

\subsubsection{Degree of Learning Engagement}

$\mathrm{Ph}$. D. students in our city have a very high degree of investment in learning. $54.62 \%$ of $\mathrm{Ph}$. D. students think they are very involved in learning. $43.85 \%$ of $\mathrm{Ph}$. D. students think they are relatively involved in learning. Only $1.54 \%$ of $\mathrm{Ph}$. D. students think they are not enough in learning. The above data are also consistent with the time allocation survey of $\mathrm{PhD}$ students during the semester [9].

\subsubsection{Dissertation Quality}

As the core index reflecting the quality of postgraduate training, dissertation has been highly valued by all postgraduate training units in our city. The quality of dissertation has also become a generally satisfactory evaluation index for doctoral students. $54.62 \%$ of the doctoral students thought that the dissertation was of high quality, $43.08 \%$ of the doctoral students thought that the dissertation was of average quality, and only $2.31 \%$ of the doctoral students thought that the dissertation was of low quality.

\subsubsection{Basic and Professional Knowledge}

The basic and professional knowledge of Ph. D. students in 
our city is relatively solid. $53.08 \%$ of $\mathrm{Ph}$. D. students think that they perform better in this respect. $44.62 \%$ of $\mathrm{Ph}$. D. students think that their performance is average. Only $2.31 \%$ of Ph. D. students think that they lack basic and professional knowledge.

\subsubsection{Scientific Research Ability}

Many universities in our city attach great importance to the scientific research of doctoral students, and doctoral students also spend a lot of time and energy in scientific research. Overall, 52.31\% of $\mathrm{Ph}$. D. students think they have strong scientific research ability, $44.62 \%$ of $\mathrm{Ph}$. D. students think they have general scientific research ability, only $3.08 \%$ of $\mathrm{Ph}$. D. students think they have poor scientific research ability [10].

\subsection{Indicators of Doctoral Students' Lower Satisfaction with Their Training Quality in Chongqing}

\subsubsection{Innovation Ability}

Innovation ability is the lowest indicator of doctoral students' satisfaction in our city. $7.69 \%$ of doctoral students think that their innovation ability is very deficient. $54.62 \%$ of doctoral students think that their innovation ability is general. Only $37.69 \%$ of doctoral students think that their innovation ability is strong.

\subsubsection{Practical Ability}

On the whole, the doctoral education in our city pays more attention to the training of academic research ability, which is less helpful to practical ability. $5.38 \%$ of the doctoral students thought that their practical ability was very deficient, $47.69 \%$ of the doctoral students thought that their practical ability was general, and $46.92 \%$ of the doctoral students thought that their practical ability was strong.

\subsubsection{Knowledge Level of Related Disciplines}

Doctoral students in our city generally believe that their professional foundation and professional knowledge are relatively solid, but the breadth of knowledge is relatively lacking. $5.38 \%$ of the doctoral students thought that they had limited knowledge of related subjects, $52.31 \%$ of them thought that they had general knowledge of related subjects, and $42.31 \%$ of the doctoral students thought that they had rich knowledge of related subjects.

\subsubsection{Sense of Mission and Responsibility}

Doctoral students in our city lack sense of mission and responsibility. $5.38 \%$ of $\mathrm{Ph}$. D. students think that they are poor in this respect, $60 \%$ of them think that they are average, $34.62 \%$ of them think that they have a strong sense of mission and responsibility.

\subsubsection{Organizational and Coordination Capabilities}

Contemporary large-scale scientific research projects can not be separated from organizational collaboration. Doctoral students'organizational and coordinating ability is an important aspect of their training quality. $4.62 \%$ of the $\mathrm{PhD}$ students thought that their organizational and coordinating abilities were poor, $57.69 \%$ of the $\mathrm{PhD}$ students thought that their organizational and coordinating abilities were general, and $37.69 \%$ of the $\mathrm{PhD}$ students thought that their organizational and coordinating abilities were strong.

\subsubsection{Foreign Language Proficiency}

Doctoral students in our city are not satisfied with their foreign language ability. The survey shows that $4.62 \%$ of $\mathrm{PhD}$ students think their foreign language proficiency is low, $49.23 \%$ of $\mathrm{PhD}$ students think their foreign language proficiency is average, and $46.15 \%$ of $\mathrm{PhD}$ students think their foreign language proficiency is high.

The results of the above survey reflect that the research and education in our city started late, and there is a certain gap compared with the developed areas. However, with the rapid economic and social development of our city in recent years, doctoral education has also developed rapidly. Doctoral students are more satisfied with academic integrity, moral level, dissertation quality, degree of investment in learning, basic and professional knowledge. They are not satisfied with innovation ability, knowledge level of related disciplines, sense of mission and responsibility, foreign language level, organization and coordination ability.

\section{Thoughts on Further Improving Doctoral Students' Satisfaction with Their Training Quality}

\subsection{Promoting Doctoral Education to Actively Adapt to the Needs of Economic and Social Development}

In order to improve the ability of doctoral education in our city to serve the needs of economic and social development and to improve the innovative ability of doctoral students, the management departments should pay more attention to demand orientation when studying and formulating the policies for the development of doctoral education in our city, meet the needs of economic construction and social development in terms of training scale, structure, quality, efficiency and culture, and actively develop the strategic research urgently needed in our city. Doctoral education in such fields as forward-looking research in the cutting-edge fields of science and technology and public welfare research on major issues of national economy and people's livelihood [11]. Secondly, we should fully consider and respect the differences between different regions, different universities, different disciplines and different types of talents, highlight their characteristics, give full play to their advantages, rationally integrate educational resources, and encourage different development modes with different characteristics and diversification. Thirdly, top-level design should be done well in education concept, training mode, talent selection, evaluation mechanism, basic research, frontier high-tech research, construction of new disciplines, innovation spirit, innovative culture, innovative methods and other aspects, so as to accurately orientate and play a leading role. 


\subsection{Further Optimizing the Doctoral Education Structure}

In the future, the trend of adjusting the discipline structure of doctoral education should be to develop basic disciplines steadily, and to further explore the cultivation of doctoral students in applied disciplines, so as to adapt to the balanced development trend of the discipline structure of doctoral students and meet the needs of building an innovative country for top-notch innovative talents [12]. On the basis of optimizing the structure of disciplines, we should continue to promote the transformation of the degree system from focusing on academic degrees to paying equal attention to both academic and professional degrees, actively and steadily expand the scale of professional degrees, increase the types of professional degrees, and promote the participation of third parties such as trade associations in doctoral training.

\subsection{Establishing a Perfect Doctoral Education Evaluation and Quality Assurance System}

One is to give full play to the role of the market in the quality assurance system, to hand over the quality constraints to the market and to the society, and to regulate the service functions and the quality of personnel training of institutions of higher learning with the market mechanism. The second is to change the function of the government in the quality system. The behavior mode of the government in the quality assurance of doctoral education should be changed from strict control to effective management. Thirdly, we should establish and improve the internal quality assurance system of colleges and universities, focusing on the construction of ideas, personnel, conditions, systems and other elements. Fourth, we should establish and develop higher education industry organizations and implement industry self-discipline [13]. Fifth, to attract social forces to participate in the quality assurance system of doctoral training. Constantly establish and improve social intermediary evaluation organizations to play the role of mass media in quality assurance.

\subsection{Setting Scientific and Reasonable Training Objectives}

The training goal is to make doctoral education a talent standard of what quality. Therefore, the training goal plays an outline role in formulating doctoral training plan and designing doctoral training mode. Guided by the needs of economic and social development, our city should speed up the revision of doctoral training objectives, and clarify the training objectives of doctoral students in different disciplines and different degree types.

\subsection{Improving Ph. D. Students' Training Modes at Different Levels and Different Types}

According to the training objectives, the training mode should be formulated, the flexible education system should be tried out, and the tutor group system should be explored, so as to realize the reform of the training mode in different levels and classifications. Academic doctoral students should participate more in research and academic exchanges, and cultivate students' independent thinking ability and innovative research ability. Doctoral students with professional degrees should innovate curriculum system and training methods according to their career orientation to meet the needs of professional talents for specific social occupations [14]. The government should increase investment in our city's production, teaching and research projects, formulate supporting preferential policies, encourage enterprises to establish postgraduate practice bases and participate in doctoral training.

\subsection{Build Academic Exchange Platform, Smooth Academic Exchange Channels, and Cultivate Compound Talents with International Vision}

Doctoral education in our city should adhere to the basic principle of cultivating innovative talents for the future and adapting to the development of modern science and technology, take stimulating academic inspiration and enlightening innovative thinking as its main purpose, enhance innovative ability, enhance communication and cooperation ability, and cultivate scientific spirit as its goal, incorporate academic exchanges into the training plan of doctoral students, and construct an independent communication for all doctoral students, with in-depth participation of tutors. Inter-professional teachers and students can work together to discuss a universal academic exchange platform on campus. To construct an extended mode of off-campus academic exchanges for doctoral students, in which the domestic high-level doctoral academic conferences are "invited in", so as to promote doctoral students to "go out" to visit and exchange with famous universities at home and abroad, expand their horizons, and enable them to devote themselves to practice bases and production lines to exercise their scientific and technological practical abilities. 5.7. Encouraging Postgraduate Innovation from the Perspective of Training Model.

The mode of doctoral education should take encouraging innovation as the core, take innovation as the important content of doctoral education assessment, fundamentally solve the problem of motive mechanism of doctoral students' learning, and strive to cultivate students' interest in professional learning, so that every doctoral student has both pressure and motive force in the process of learning [15]. Schools should pay attention to the improvement of doctoral students' comprehensive quality, and the evaluation of doctoral students should be carried out in a comprehensive and systematic way. In practical work, students' education management can not be arranged by teachers too much, but should play the role of students' self-management, self-education and self-service, especially to mobilize the enthusiasm of doctoral students, give them more practice platforms, and promote the comprehensive improvement of doctoral students' innovation ability.

\section{Conclusion}

Higher quality of doctoral training in Chongqing: the 
survey results show that academic integrity level is the most satisfactory aspect for doctoral students during the semester, $70 \%$ of doctoral students say they perform better in academic integrity, $30 \%$ of doctoral students say they perform generally, and no doctoral students think they perform poorly in academic integrity. The results show that the doctoral students are satisfied with their ideological and moral level during the semester, $57.69 \%$ of them think their ideological and moral level is high, $42.31 \%$ of them think their ideological and moral level is general, and no doctoral students think their ideological and moral level is very poor. The data shows that $54.62 \%$ of doctoral students think they are very committed to learning, $43.85 \%$ think they are relatively committed to learning, and only $1.54 \%$ think they are not enough. The above data are consistent with the results of the time allocation survey of doctoral students during the semester. As the core index reflecting the quality of postgraduate training, dissertation has been highly valued by all graduate training units in our city, and the quality of dissertation has become a generally satisfactory evaluation index for doctoral students. $54.62 \%$ of doctoral students think the quality of dissertation is high, $43.08 \%$ of doctoral students think the quality is average, only $2.31 \%$ of doctoral students think the quality of dissertation is low. The basic and professional knowledge of doctoral students in our city is relatively solid, $53.08 \%$ of them think that they perform well in this respect, $4.62 \%$ of them think that they perform generally, and only $2.31 \%$ of them think that they are lack of basic and professional knowledge. The universities in our city pay more attention to the scientific research of doctoral students, who also spend a lot of time and energy in scientific research. In general, $52.31 \%$ of doctoral students think that they have strong scientific research ability, $44.62 \%$ of them think that their scientific research ability is average, and only $3.08 \%$ of them think that their scientific research ability is poor.

In terms of poor quality of doctoral training in Chongqing: innovation ability is the worst indicator of doctoral performance in Chongqing. $7.69 \%$ of doctoral students think their innovation ability is very poor, $54.62 \%$ of them think their innovation ability is average, only $37.69 \%$ of them think their innovation ability is strong. On the whole, the doctoral education in our city pays more attention to the training of academic research ability, which is less helpful to the practical ability. $5.38 \%$ of doctoral students think that their practical ability is very poor, $47.69 \%$ of them think that their practical ability is general, $46.92 \%$ of them think that their practical ability is strong. The doctoral students in our city generally think that they have a solid foundation and professional knowledge, but lack in the breadth of knowledge. $5.38 \%$ of doctoral students think that they have limited knowledge of related disciplines, $52.31 \%$ of them think that they have general knowledge of related disciplines, $42.31 \%$ of them think that they have rich knowledge of related disciplines. The doctoral students in our city lack a sense of mission and responsibility. $5.38 \%$ of $\mathrm{Ph}$. D. students think that their performance is very poor, $60 \%$ of them think that their performance is average, $34.62 \%$ of them think that they have a strong sense of mission and responsibility. Nowadays, large-scale scientific research projects are inseparable from organization and coordination. The organization and coordination ability of doctoral students is an important aspect of their training quality. $4.62 \%$ of doctoral students think that their organization and coordination ability is poor, $57.69 \%$ of them think that their organization and coordination ability is general, $37.69 \%$ of them think that their organization and coordination ability is strong. The foreign language ability of doctoral students in our city is poor. According to the survey, $4.62 \%$ of doctoral students think their foreign language level is low, $49.23 \%$ think their foreign language level is average, $46.15 \%$ think their foreign language level is high.

\section{Acknowledgements}

This paper is part of the research results of the key topics of the Chongqing Graduate Education and Teaching Reform Research Project, "The Report on the Development of Graduate Education Quality in Chongqing" (No. yjg152029) and "The Research on the Development of Graduate Education Quality in Chongqing in 2016" (No. yjg20162033).

\section{References}

[1] Huang Baoyin. A New Era of the Development of Professional Degree Graduate Education in China. Degree and Graduate Education, 2010 (10): 1-7.

[2] Wang Zhanjun, Li Minglei. Graduate Quality Assessment: Model and Framework. Higher Education Research, 2012 (03): $50-62$.

[3] Chen Dilong et al. Construction and practice of quality assurance system for master degree postgraduates in clinical medicine, degree and postgraduate education, 2011, (7): 73-75.

[4] Chen Dilong, Xie Peng, Wang Ling and others. Construction and practice of quality assurance system for postgraduate training of clinical medicine. Degree and postgraduate education. 2011. (7): 69-71.

[5] Hu Weili, Chen Dilong, Chen Yiting, et al. Difficulties and Countermeasures of "two-track integration" between postgraduate education of clinical medicine degree and standardized resident training. Degree and postgraduate education. 2013, (2): 41-45.

[6] $\mathrm{Hu}$ Guangli, Li Haiyan. Problems and Countermeasures in postgraduate education of clinical medicine. Journal of postgraduate medicine. 2013, 11: 1196-1198.

[7] Hong Xin, Bi Yutian. Practice and exploration of objective structured examination for medical students. Chongqing Medical Science. 2009, (38): 1983-1984.

[8] Chen Qi, Shen Chunming, Chen Dilong et al. Construction and practice of five quality assurance systems for postgraduate education of clinical medicine degree. Chongqing Medical Science. 2013, (13): 1555-1556. 
[9] Yang Shuhua, Li Bili, Cao Xiufeng, et al. Training and assessment of clinical competence of postgraduates with clinical medicine degree. China Higher Medical Education. 2010, (2): 135-136.

[10] Bai Juan, Cao Shan and Lu Bao Equality. Improvement and practice of clinical competence assessment system for postgraduates majoring in clinical medicine. Health vocational education. 2014, (32): 8-10.

[11] Liu Ying. Construction and practice of clinical competence assessment system for master's degree postgraduates in clinical medicine. China Health Management. 2014, (3): 216-218.

[12] Dong Jingzhu, Zhang Donghua, Fang Ming et al. Establishment and application of clinical competence evaluation system for master's degree postgraduates in clinical medicine. China Higher Medical Education. 2013, (6): 115-116.

[13] Guo Hangyuan, Chi Jufang. Strengthening general practice education to train high-quality general practitioners. Zhejiang Clinical Medicine, 2008, 10 (7): 1006-1007.

[14] Down SM, Marasigan F, Abraham V, et al. Scoring performance on computer-based patient simulations: Beyond value of information. Proc AMIA Symp 1999; 520-524.

[15] Dato N. M. de Gruijter and Leo J. Th. van der Kamp, Generalizability Theory, Advance in Educational and Psychological Testing. Theory and Applications, 1990: 45. 